\title{
Disclosure of Intellectual Capital in Annual Reports: An Exploratory Study of Indian IT Corporations
}

\author{
Prof. Dr. Madan Lal Bhasin \\ Bang College of Business-KIMEP \\ Dostyk Building, Abay Avenue 2, \\ Almaty 050010, Republic of KAZAKHSTAN \\ Mobile: 7+77078788440 E-mail: madan.bhasin@rediffmail.com
}

\begin{abstract}
Knowledge, innovation, information technology, and people are the key contributories in the future of any organization, and IC is the key driver of market value in the "knowledge" economy. Voluntary disclosure of IC information in the annual reports is done by a few leading corporations. The omission of IC information, therefore, may adversely influence the quality of decisions made by shareholders, or lead to material misstatements.

This study attempts to provide an insight into the "narrative" style of IC disclosures done by the Indian corporations. In order to survey the recent IC disclosure scenario, we conducted a study of 16 Indian IT corporations in which the 'content analysis' was done on their 2007 to 2009 annual reports. The results of this study confirmed that IC disclosure by these IT corporations is almost negligible and its disclosure had not received any preference from the mentors of these corporations. IC reports may initially be used for 'internal' management purposes; but an 'external' stakeholder-focus of IC report should be the ultimate goal.
\end{abstract}

JEL Classifications: O34; O33; O53; D8; H83; L63

Keywords: Intellectual capital, disclosure scenario, IT corporations, India, IC reports

\section{Introduction}

Intellectual capital (IC) can be a source of competitive advantage for businesses and stimulate innovation that leads to wealth generation (Marr et al., 2003). However, the disclosure of IC is relatively new, with a smattering of pioneering corporations using the "newer" measures. Disclosure of IC information comprises all forms of "voluntary" corporate communications. It is universally accepted that all material issues relating to IC of the enterprise should be disclosed in a timely fashion: the disclosure should be clear, concise, precise, and governed by the substance over form principle. Thus, corporate managements widely recognize that there are several economic benefits to be gained from a well-managed IC disclosure policy. A detailed and structured system of disclosure enables investors to understand, and obtain accurate and reliable information of corporations in order to make "better" investment decisions. In the past, some research studies have shown that with increased corporate disclosures, firms experience a reduction in cost of equity capital, as well as, cost of debt. Similarly, some experts found a beneficial increase in the firm's stock liquidity and performance. In addition, it is universally accepted that information disclosure in itself is a strategic tool, which enhances a corporation's ability to raise capital at the lowest possible cost. Disclosure of voluntary information enables the shareholders' to evaluate the management's performance by observing, how efficiently the management is utilizing the resources in the overall interest of the principal?

Published annual reports are used as a medium for communicating both quantitative and qualitative corporate information to shareholders, potential shareholders (investors) and other users. It is a key objective of accounting rules to ensure that users' have sufficient and timely availability of information in order to participate in the market on an informed basis. However, information and its disclosure are the areas where corporate law and accounting regulatory bodies should join hands together. To quote FASB, "the quality of financial and non-financial disclosures depends significantly on the robustness of the reporting standards on the basis of which the financial/non-financial information is prepared and reported." 
Although publication of an annual report is a statutory requirement, corporations normally "voluntarily" disclose information in excess of the mandatory requirements. However, the location of IC disclosures within the annual report of a corporation is not generally well-defined, and can vary substantially across country in practice. However, some degree of harmonization of the location of CG disclosures would be desirable to make the relevant data more accessible, in the long-run. Two possible approaches include: first, putting all IC disclosures in a "Separate Section" of the Annual Report, and second, in a stand-alone "IC Report". Where IC disclosures are not consolidated, there should be sufficient cross-referencing to different disclosures so as to improve access to the information. Even where IC disclosure requirements exist, there is usually substantial latitude afforded to managers in relation to the quality and quantity of disclosure about corporate-specific practices.

\section{Literature Review on IC Disclosure Studies}

The main IC disclosure research studies were typically cross-sectional and country-specific, although some longitudinal studies have been reported too. Some of the leading IC disclosure studies, widely reported in the literature, were conducted in Australia, UK \& Ireland, Sweden, Canada, Malaysia, Sri Lanka, New Zealand, Bangladesh and India. While most studies employed "content analysis" as the research methodology, other studies have used questionnaire surveys (Beattie 2007, p.5). Despite the fact that the importance of IC has increased in recent times, there are inadequate disclosures of IC in the financial statements of corporations (Bruggen et. al. 2009).

In a review of the current state of financial and external disclosure research, Parker (2007) identified IC accounting as a major area for further research. However, most of the IC disclosure studies were cross-sectional and country-specific. Examples include studies in Australia (e.g. Guthrie and Petty, 2000; Sujan and Abeysekera, 2007), Ireland (Brennan, 2001), Italy (e.g. Bozzolan et al., 2003), Malaysia (Goh and Lim, 2004), UK (e.g. Williams, 2001), and Canada (Bontis, 2003). Relatively very few longitudinal studies have been reported (e.g. Abeysekera and Guthrie, 2005). Moreover, some studies focused on the specific aspects of IC disclosure, such as human capital disclosure (e.g. Subbarao and Zeghal, 1997), while others conducted international comparative studies (e.g. Vergauwen and van Alem, 2005; Cerbioni and Parbonetti, 2007). Some IC disclosure studies have looked beyond annual reports to examine other communication channels, such as, analyst presentations. Guthrie and Petty's (2004, p. 286) analysis of IC disclosure practices suggests that disclosure has been expressed in discursive rather than numerical terms and that little attempt has been made to translate the rhetoric into measures that enable performance of various forms of IC to be evaluated.

India presents an ideal case for the analysis of IC disclosures by the IT corporations because the economy has been undergoing rapid economic transformation in the financial services, tourism, IT sectors and the niche manufacturing gaining momentum. In the Indian-context, there has been very limited number of IC disclosure studies, as compared to its European counterparts. However, two recent studies are available on IC disclosure in India using content analysis, which were done by Kamath (2008), and Joshi et al. (2009). The foregoing discussion suggests that the literature on the determinants of IC disclosure in Indian-context is very limited and inconclusive. Thus, our study builds on the previous literature of IC disclosure practice and overall IC disclosure scenario in the Indian corporate sector, especially knowledge-based IT firms. The scope of the study has been confined to 16 corporations from the IT sector, and a content analysis was performed on their annual reports for two years, namely, 2007-08 and 2008-09 respectively.

\section{Research Methodology}

With the rise of the "knowledge economy," the management of IC is becoming even more important and, therefore, it should be disclosed in the annual reports. In the knowledge-based economy, therefore, most of the organizations have realized that the true potential of creating value for 
their organizations lies in the measurement, valuation, and disclosure of their IC (Jing et al., 2007). Knowledge, innovation, information technology, and people are key contributories in the future of any organization and IC is the key driver of market value in the knowledge economy.

This research aims at mapping the current state of IC-related disclosures in the Indian information-technology (IT) sector. Accordingly, the sample-size of this study consists of 16 top ITsector corporations. However, these corporations were primarily selected on the basis of their total income, as per the 2008 publication of "Dun and Bradstreet," a premier survey agency of the country. The electronic/soft copies of the annual reports for these selected corporations were obtained for two years, 2007-08 and 2008-09 from their respective corporate Websites. In the past, several research studies have been conducted in various countries, using the "content analysis" of annual reports, to analyze the IC disclosure practices. A list of IC related terms was searched within the annual reports yielding a significantly small number of instances in which IC disclosure took place. Therefore, an attempt has been made here to use the same technique (i.e., content analysis) to analyze the extent of disclosure of IC by these IT corporations. However, research in other countries revealed that disclosure practice stays well behind on a global scale, despite the perceived importance by corporate managers.

\section{Study of IC Disclosures Done by the IT Corporations in India}

In the knowledge economy, most of the organizations have realized that the true potential of creating value for their organization lies in the measurement, valuation and disclosure of their IC. Therefore, measurement and disclosure of IC is no more a choice but imperative for the IC driven firm's performance. Nielsen et al., (2006) very forcefully asserts: "Annual reports are an ideal place to apply an IC framework because they allow us to compare IC positions and trends across different corporations, industries and countries. They are an instrument for communicating issues comprehensively and concisely, and they are produced regularly, so they can be used to analyze management attitudes and policies across reporting periods."

The key objective of the present study was "to survey the prevailing practices of IC disclosure made by the information-technology (IT) corporate sector in India." The sample-size of this study consists of 16 IT corporations from India. They were primarily selected on the basis of their total income as per the 2008 publication of "Dun and Bradstreet," a premier survey agency of the country. The annual reports of the selected corporations were obtained directly from the Websites of these corporations, and the annual reports for two years (2008 \& 2009) were examined.

The "content analysis" of annual reports involves codification of qualitative and quantitative information into pre-defined categories in order to derive patterns in the presentation and reporting of information (Joshi et al., 2010). Moreover, the coding process involved reading the annual report of each corporation and coding the information according to pre-defined categories of IC. Over the last decade, content analysis has been used by several leading researchers to study the IC performance and reporting (Beattie 2006). Therefore, as part of the present study, "content analysis" has been used to analyze the extent of IC disclosure by the IT corporations. By looking at the disclosure of terminology within their annual reports, one can examine the extent to which Indian corporations publicly document the presence (or importance) of IC. In identifying corporations disclosing IC, a list of related "IC-terminology" was compiled. Subsequently, a survey and review of several IC books and articles was conducted. According to Bontis (2003), "The panel of researchers from the World Congress on Intellectual Capital finalized the list of IC items into a collection of 39 terms that encompassed much of the IC literature." The list used by Bontis was considered comprehensive for this type of research on knowledge-based information-technology corporations. The final list of IC terms is shown in Table-1. Each of these terms was "electronically" searched individually in the annual reports to find out the presence or absence of the said terms, and count of how many times. By and large, most IC terms were disclosed only once in each annual report, and there was lack of consistency about the terms disclosed. Results were tabulated on the basis of the number of 
corporations disclosing these terms in their annual reports. Corporation-wise analysis, along with testing the degree of variance, has also been undertaken. The content-wise analysis has been shown in Table-2, corporation-wise analysis in Table-3, and the variation in disclosure has been presented in Table-4.

Table 1. The intellectual capital--39 search terms

\begin{tabular}{|l|l|l|}
\hline Business Knowledge & Employee efficiency & Intellectual property \\
\hline Corporation reputation & Employee skill & Intellectual resources \\
\hline Competitive intelligence & Employee value & KM \\
\hline Corporate learning & Knowledge assets & Expert networks \\
\hline Corporate university & Expert teams & Knowledge management \\
\hline Cultural diversity & Knowledge sharing & Human assets \\
\hline Customer capital & Knowledge stock & Human capital \\
\hline Customer knowledge & Management quality & Human value \\
\hline Economic Value added & IC & Organizational culture \\
\hline Employee expertise & Information systems & Organizational learning \\
\hline Employee know-how & Relational capital & Intellectual assets \\
\hline Employee knowledge & Intellectual capital & Structural capital \\
\hline Employee productivity & Intellectual material & Superior knowledge \\
\hline
\end{tabular}

Source: Bontis, Nick, "Intellectual Capital Disclosure in Canadian Corporations," Journal of Human Resource Costing and Accounting, 2003, page 7

\section{Findings of Study and Analysis of Results}

Table-2 indicates that only $18(46 \%)$ items, out of the total list of 39 IC-terms, were disclosed in the annual reports of the 16 Indian IT corporations. Most of the IC-terms (viz., business knowledge, employee productivity, employee skill and value, knowledge assets, management quality, KM, human value, organizational learning, and intellectual assets) were disclosed only "once" in the annual reports, and there was utmost "lack of consistency" across-time about the terms disclosed. Our findings are very much similar to the findings of other studies done in the past. Surprisingly, the most popular term disclosed in this study was "intellectual property rights (IPR)," which represents such intangibles as patents, brands valuations, and the outcomes of R\&D investment. This is quite obvious due to the vital role played by the "intangible assets (or IC)" in the case of knowledge-intensive IT corporations. However, this term has a very specific legal connotation from an accounting and legal perspectives. Therefore, the term "intellectual property" (IC term no. 27) had the maximum (93\%) disclosure done by all the 16 IT corporations, followed by the $50 \%$ disclosure of the term "information systems" (IC term no. 23). This was not surprising due to the nature of knowledge-based IT corporations under study.

Table 2. Content-wise analysis of intellectual capital terms disclosure 


\begin{tabular}{|c|c|c|}
\hline S. No. & Items of Intellectual Capital & No. of Corporations Disclosing \\
\hline 1. & Business Knowledge & 1 \\
\hline 2. & Corporation reputation & Nil \\
\hline 3. & Competitive intelligence & Nil \\
\hline 4. & Corporate learning & Nil \\
\hline 5. & Corporate university & Nil \\
\hline 6. & Cultural diversity & Nil \\
\hline 7. & Customer capital & Nil \\
\hline 8. & Customer knowledge & Nil \\
\hline 9. & Economic Value added & 3 \\
\hline 10. & Employee expertise & Nil \\
\hline 11. & Employee know-how & Nil \\
\hline 12. & Employee knowledge & Nil \\
\hline 13. & Employee productivity & 1 \\
\hline 14. & Employee efficiency & Nil \\
\hline 15. & Employee skill & 1 \\
\hline 16 & Employee value & 1 \\
\hline 17. & Knowledge assets & 1 \\
\hline 18 & Expert teams & Nil \\
\hline 19. & Knowledge sharing & 3 \\
\hline 20. & Knowledge stock & Nil \\
\hline 21. & Management quality & 1 \\
\hline 22. & IC & Nil \\
\hline 23. & Information systems & 8 \\
\hline 24. & Relational capital & Nil \\
\hline 25. & Intellectual capital & 2 \\
\hline 26. & Intellectual material & Nil \\
\hline 27. & Intellectual property & 15 \\
\hline 28. & Intellectual resources & Nil \\
\hline 29. & KM & 1 \\
\hline 30. & Expert networks & Nil \\
\hline 31. & Knowledge management & 5 \\
\hline 32. & Human assets & Nil \\
\hline 33. & Human capital & 6 \\
\hline 34. & Human value & 1 \\
\hline 35. & Organizational culture & 2 \\
\hline 36. & Organizational learning & 1 \\
\hline 37. & Intellectual assets & 1 \\
\hline 38. & Structural capital & Nil \\
\hline 39. & Superior knowledge & Nil \\
\hline
\end{tabular}

Source: Compiled by the author from the Annual Reports of Corporations for the year 2007-2008 and 2008-2009

Unfortunately, the term "intellectual capital (IC)," was specifically disclosed by just 2 out of the 16 corporations, namely, Moser Baer India Limited, and Patni Computer System Limited. A closer examination of both these corporations clearly revealed that the presence of "IC" term was generally used in the "management discussion \& analysis (MD\&A)" section of the annual reports. It is very strange, there is no evidence at all in any of the firms identified, that an actual IC statement/report was developed, or that any other IC metrics were being published. Moreover, our survey and subsequent analysis of the IC disclosure practices suggests that disclosure has been vaguely expressed in very "discursive," rather than "numerical" terms, and that little or no attempt has been made to translate the rhetoric into measures that enable performance of various forms of IC to be evaluated. 
For instance, Moser Baer India Limited declared in its annual report, under the MD\&A section, for the year 2007-08 as: "Quality of our human resources charts the success and growth potential of our business. The Corporation has managed to keep attrition rates well in control by imbibing a sense of ownership and pride, and strong HR initiatives geared to nurturing latent talent, and unlocking the power of IC. The Corporation continues to drive organization development and also build management resources for a multi-business enterprise." Recently, Moser Baer had stated in its 200809 annual report, as follows: "Your corporation continuously benchmarks HR policies and practices with the best in industry and carries out necessary improvements to attract and retain best talent and build intellectual capital." Similarly, another IT corporation, Patni Computer Systems Limited makes a "casual" mention of its IC in its annual report for the year 2007-08 as under: "The global sourcing market has matured from those days when India was considered to be a source of 'low-cost manpower'. Today, it has earned the distinction of being a 'preferred destination for intellectual capital' that accelerates the trend-globalization of services. Going ahead, Indian corporations are bracing up for the challenge of providing end-to-end business domain-focused solutions, leveraging intellectual property (IP) in form of solution accelerators, frameworks and service delivery technologies."

Table 3. Corporation-wise analysis of intellectual capital terms (count of disclosures)

\begin{tabular}{|l|l|l|c|}
\hline S. No. & Name of Corporation & Terms of IC Disclosure (Count of Item) & $\begin{array}{c}\text { Total No. of IC Terms } \\
\text { Disclosed }\end{array}$ \\
\hline 1 & Infosys Technologies Limited & $\begin{array}{l}1(1), 9(6), 16(2), 17(2), 19(1), 21(1), \\
23(8), 27(15), 29(3), 31(7), 33(6), \\
36(1), 37(1)\end{array}$ & 13 \\
\hline 2 & Moser Baer India Limited & $25(1), 27(1), 33(4), 34(1), 35(1)$ & 05 \\
\hline 3 & $\begin{array}{l}\text { Patni Computer Systems } \\
\text { Limited }\end{array}$ & $23(1), 25(1), 27(10)$ & 03 \\
\hline 4 & $\begin{array}{l}\text { Tata Consultancy Services } \\
\text { Limited }\end{array}$ & $9(2), 23(1), 27(5), 31(5), 33(1)$ & 05 \\
\hline 5 & Wipro Limited & $27(5)$ & 01 \\
\hline 6 & HCL Infosystems Limited & $23(1)$ & 01 \\
\hline 7 & MphasiS Limited & $23(2), 27(2), 35(1)$ & 03 \\
\hline 8 & CMC Limited & $19(1), 27(1)$ & 02 \\
\hline 9 & Polaris Software Lab Limited & $15(1), 23(1), 27(14)$ & 03 \\
\hline 10 & $\begin{array}{l}\text { Siemens Information System } \\
\text { Limited }\end{array}$ & $23(2), 27(1)$ & 03 \\
\hline 11 & $\begin{array}{l}\text { Financial Technologies } \\
\text { (India) Limited }\end{array}$ & $23(2), 25(1), 27(3)$ & 03 \\
\hline 12 & I-Flex Solutions Limited & $27(1), 31(2), 33(2)$ & 01 \\
\hline 13 & $\begin{array}{l}\text { Satyam Computer Services } \\
\text { Limited }\end{array}$ & $27(1)$ & 01 \\
\hline 14 & Tech Mahindra Limited & $27(4)$ & 02 \\
\hline 15 & HCL Technologies Limited & $27(3), 33(1)$ & 06 \\
\hline 16 & $\begin{array}{l}\text { Larsen \&Toubro Infotech } \\
\text { Limited }\end{array}$ & $9(2), 13(2), 19(1), 27(4), 31(1), 33(1)$ & \\
\hline
\end{tabular}

Source: Compiled by the author from the Annual Reports of Corporations for the year 2007-08 and 2008-09

The term "knowledge management (KM)" (IC term no. $31 \& 29$ ), which is supposed to occupy a place of prominence in the knowledge-based IT corporations of India, was disclosed by a meager 6 (37\%) corporations. However, most of the terms relating to the employees (except employee productivity, skill, value), and customers could not find any deserving place in the annual reports of the selected corporations. The most important constituents of IC-relational capital, structural capital 
and customer capital - did not figure even once in any of the annual reports of the corporations under study.

Table-3 very clearly highlights that Infosys Technologies Limited, a corporation acclaimed widely by the international community and the media too, had disclosed the maximum number (13) of IC-related items from the total list of 39 items. It is worth mentioning here that Infosys was the first Indian corporation to win the 'Most Admired Knowledge Enterprise in Asia' award in the year 2002. However, it is surprising to note that this corporation did not make any mention of term "IC" in its annual reports for the years 2007 to 2009. Perhaps, Infosys is the only IT-corporation in India, which has been regularly disclosing its "Intangible Assets Score Sheet," as a measure of intangible assets (or IC). For example, the corporation in its 2008-09 annual report makes the following remarks: "We published models for valuing two of our most important intangible assets - human resources and the "Infosys" brand. This score sheet is broadly adopted from the intangible asset score sheet provided in the book titled, 'The New Organizational Wealth,' written by Dr. Karl-Erik Sveiby and published by Barrett-Koehler Publishers Inc., San Francisco. We believe such representation of intangible assets provides a tool to our investors for evaluating our market-worthiness."

Table 4. Variation in item-wise disclosure

\begin{tabular}{|c|c|}
\hline Number of Items Covered & $\begin{array}{c}2007 \text { to } 2009 \\
\text { No. of Disclosing } \\
\text { Corporations }\end{array}$ \\
\hline $0-3$ & 7 \\
$3-6$ & 6 \\
$6-9$ & 1 \\
$9-12$ & 0 \\
$12-15$ & 1 \\
\hline Mean Disclosure & 3.9 \\
\hline Standard Deviation & 3.12 \\
\hline Coefficient of Variation & $80 \%$ \\
\hline
\end{tabular}

Source: Compiled by the author from the Annual Reports of Corporations for the year 2007-2008 and 2008- 2009

Based on the "content analysis" of this study, Larsen \& Toubro Infotech Limited disclosed the second-highest 6 out of 18 (33\%) IC-terms, which were followed up by Tata Consultancy Services and Moser Baer India Limited, respectively, both with a disclosure score of 5 out of 18 IC-terms. However, we are surprised to note that Patni Computers Limited, MphasiS Limited, I-Flex Solutions Limited, Polaris Software Lab Limited and Financial Technologies (India) Limited, by far comprising the largest segment of the IT corporations having 6 corporations from the sample size of 16 corporations, disclosed just 3 out of 18 IC-related terms in their annual reports for the period of study. Rest of the 7 corporations, forming a big chunk of our study, disclosed in the range of just 1 to 2 terms, as for as the disclosure of IC-terms are concerned. For example, CMC Limited, Siemens Information System Limited and HCL Technologies Limited disclosed just 2 items, while only 1 item was disclosed by Wipro Limited, HCL Infosystems Limited, Satyam Computer Services Limited, and Tech Mahindra Limited. It is also important to note that the disclosed IC items have been shown at widely "scattered-places" in the annual reports, and there appears to be an utmost "lack of consistency" across-time regarding the terms disclosed. The "mean" disclosure, as shown in Table-6, comes to be as low as 3.9 items. There is a variation of 3.12 items, on average, as suggested by the value of "standard deviation". The "coefficient of variation" comes to be as high as $80 \%$, which indicates a significant variation in item-wise disclosure in the annual reports of the corporations. However, there is no "specific" disclosure of IC as a special part or content of the annual report, despite its very high relevance in the knowledge-intensive IT industries.

Mr. Nandan Nilekani, CEO, President and MD of Infosys Technologies remarked: "At Infosys, we are effectively transforming enterprise knowledge into wealth-creating ideas, products and 
solutions. We are building portfolios of intellectual capital (IC) and intangible assets, which will enable them to out-perform their competitors in the future. We consider KM as a powerful medium for creating sustainable networks of people across intra-organizational boundaries. It also provides a symbolism for aligning individual initiative and creativity with organizational growth." Thus, Infosys has been duly recognized for its organizational learning and for transforming enterprise knowledge into shareholder value. It is worth mentioning here that Infosys is regularly disclosing in its annual report details about the "Intangible Assets Score-Sheet," as developed by Dr. Seveiby, human resources accounting, brand valuation, etc.

Similarly, Mr. Sambuddha Deb, Chief Quality Officer, Wipro Technologies, observed: "Our knowledge management initiative continues to be one of the most strategic initiatives and our knowledge portal, "Knet," provides an effective and efficient means of capturing knowledge, both tacit and explicit across the organization, distilling it through a review process and making it available in a form which is ready to use. Our conscious and significant investment in the KM initiative is providing an important edge that the business needs." No doubt, comprehensive IC disclosures would not only help in retaining the competitive advantage in the long-run, when other firms start emulating such pioneering practices, but it would also prove as an added information available, which can also be used to measure the link between the performance, growth and stability of the firm with its IC.

Based on the results of the present research study, the following broad generalizations can be made: (a) IC disclosure is very much an academic discussion; (b) There is no evidence at all that IC disclosure has generated any traction for Indian corporations; (c) IC reports published by the Indian corporations is almost negligible; and (d) IC disclosure has not received any priority from the mentors of the Indian corporations. Obviously, using the language of IC is an important antecedent to developing IC reports, but Indian corporate sector seems to be significantly behind its Scandinavian and other counterparts. We are hopeful that as the field of IC gains momentum, disclosure of IC evidence would also gradually increase. However, the average number (3.9) of items reported by the Indian IT-sector corporations is very low, which suggests that there is neither awareness nor any interest to record and report IC variables by these corporations. Even the few items which were just reported were expressed in "discursive" rather than in "numerical" terms. Moreover, it has also been found that there exists no clear-cut pattern or system of IC disclosure in the annual reports. The disclosure was not uniform and no evidence of its well-defined measurement basis (except for the Infosys "Intangible Score-Card") was found in the annual reports. It is very surprising to note that the Information Technology corporations, which are most dominating group in the knowledge sector, have failed to report IC in their annual reports. Undoubtedly, Indian corporations are far lagging behind in the field of measurement, management and disclosure of IC, as compared to the Scandinavian and/or European corporations. Thus, there is an urgent need to highlight the importance of IC disclosure to these knowledge-based IT firms and encourage them to provide "voluntary" IC disclosures.

Surprisingly, our findings are very similar in comparison to the various other studies on the same subject (viz., Bontis, 2003, Brennan, 200, Ordonez de Pablos, 2002, Kamath, 2008 etc.), which also signify very low level of IC disclosures. For instance, as per the OECD (1999) research report, "corporations in the Europe are way ahead of their counterparts elsewhere when it comes to the measurement, disclosure and management of their IC." While there is some evidence that Australian enterprises are engaging in the process of identifying their stock of IC, overall Australian corporations do not compare favorably with their overseas counterparts in their ability to manage, develop, support, measure and report their IC (Bruggen et al., 2009). Similarly, Bontis (2003) concludes: "There is no evidence at all that IC disclosure has garnered any traction for the Canadian corporations. Only a small percentage of Canadian corporations (68 out of 10,000) even used the terms in their annual reports. Obviously, using the language of IC is an important antecedent to developing IC statements, but Canada seems to be significantly behind its Scandinavian counterparts." 


\section{Conclusion and Recommendations}

Leading IT corporations from India that were applying IC measures have found that it gives them better understanding of the "drivers of value" and is improving management and growth of these vital assets. Both, Wipro Technologies Limited and Infosys Technologies Limited have been recognized for their organizational learning and for transforming enterprise knowledge into shareholder value. Unfortunately, IC disclosure in the Indian IT firms, for the period of study, is seen to be almost negligible and partial, in tune with the developed countries. Only a small number of the total firms studied actually reported IC-related terms. Moreover, the disclosure of IC was not at all uniform, and there is lack of evidence regarding the usage of the measurement, management techniques, and tools by these firms. Thus, there is an urgent need to highlight the importance of IC disclosure to these knowledge-based IT firms and encourage them to provide voluntary IC disclosures. A brief summary of the present research study reveals the following aspects:

- The "key" components of IC are poorly understood, inadequately identified, inefficiently managed, and are not reported within a consistent framework.

- The extent of disclosure is generally 'minimum' but the types of IC that tend to be most often reported include human resources, technology and intellectual property rights, and organizational and workplace structure.

- A review of industry clusters within the study suggests that no individual industry is significantly ahead of any other in its IC disclosure practices.

- By and large, most corporation representatives believe that the management of IC is an important factor in determining future corporation success and facing competitiveness. However, few executives are able to identify initiatives within their organization that are designed to assist in managing IC.

- IC disclosures made by the Indian IT firms is very "negligible, partial, and descriptive, lack of consistency in reporting etc.," in sharp contrast with the developed countries. A very small number of the total firms studied actually reported IC-related terms, disclosure was not uniform, and there is lack of evidence regarding the usage of the measurement, management techniques, and tools by these firms.

So far, published guidelines represent good initiatives undertaken by the academics based on the experience of some pioneer firms in developed countries that build the IC report. They provide practical guidelines on how to measure and report IC. However, firms are not enforced to follow these guidelines, and therefore, they just offer an orientation. The development of a set of homogeneous norms, principles, indicators and structure is a high priority in the IC report agenda. The following recommendations are made

- Even though, IC has a very strong impact on the drivers of future earnings, but unfortunately, it is largely ignored in the financial disclosure. We strongly recommend that corporations must create a culture that emphasizes the importance of IC in achieving business advantage.

- Those corporations that are concerned with their relationship with the capital markets are to develop 'strategic' and 'tactical' initiatives that provide for 'voluntary' IC disclosures.

- The IC reports may initially be used for "internal" management purposes but an "external" stakeholder focus report should be the long-term ultimate goal.

- The professional accounting bodies, at the global level, should join hands to develop an internationally accepted valuation system, and standardized and harmonized approaches for disclosure of IC.

- The regulatory bodies should establish "key" parameters for the disclosure of IC in a similar fashion, as have been defined for disclosure of Corporate Governance (CG), as per Clause 49 of the Securities Exchange Board of India (SEBI) in order to make a beginning in the field.

- To adopt "voluntary" IC disclosure practices, especially for Indian IT firms in the knowledgesector, where competitiveness of the firms are determined by their intangible assets. 
Indeed, the whole field of IC disclosure is still relatively 'new' and very slowly evolving. Therefore, accountants, business managers, and policy makers have all to grapple with its concepts, philosophy, and detailed methodologies for IC applications. If efforts are not made towards incorporating the value of IC (a vital intangible) into a "formalized" disclosure framework then, for many public and private sector organizations, the management's disclosures made in the financial statements will become increasingly irrelevant as a tool supporting meaningful decision-making. Reallife corporate experience suggests that rushing into the details of IC measurement, before understanding the fundamentals, is going to prove counter-productive. Now, we feel the time is ripe for international professional bodies to develop that understanding and to develop new measures that will guide them more clearly to a prosperous future. Hence, the development of a set of homogeneous norms, principles, indicators, structure, and methodologies must be assigned a very high priority area in the IC report agenda.

\section{References}

[1] Beattie, V, and Thomas, S.J. (2006) 'Lifting the lid on the use of content analysis to investigate intellectual capital disclosures' Discussion Paper Series in Accounting \& Finance, Heriot-Watt University, School of Management and Languages, September, URL: http//www.sml.hw.ac.uk/ research/discussion/DP2006-AF01. Pdf.

[2] Bernard, M, Dina, G. and Andy N. (2003) 'Why do firms measure their intellectual capital?' Journal of Intellectual Capital, Vol. 4, No. 4, pp. 441-464.

[3] Bontis, Nick (2003) 'Intellectual capital disclosure in Canadian corporations', Journal of Human Resource Costing and Accounting, Vol. 7, No. 1, pp. 9-20.

[4] Bruggen, A., Vergauven, P., and Dao, M., (2009) 'Determinants of intellectual capital reporting: evidence from Australia', Management Decision, Vol. 47, No. 2, pp. 233-245.

[5] CMC Limited. 'Annual reports for the year 2007-08 and 2008-09'. Available at the Corporation Website: http://www.cmcltd.com/.

[6] Financial Accounting Standards Board (FASB) (2001) 'Improving business reporting: insights into enhancing voluntary disclosure,' Business Reporting Research Project, Steering Committee Report, Financial Accounting Standards Board, pp. 1-50.

[7] Financial Technologies (India) Limited. 'Annual reports for the year 2007-08 and 2008-09.' Available at the Corporation Website: http://www.ftindia.com/.

[8] Guthrie J., Petty, R. Yongvanich, K. and Ricceri, F. (2004) 'Using content analysis as a research method to inquire into intellectual capital reporting', Journal of Intellectual Capital, Volume 5, No. 2, pp. 282-293.

[9] HCL Infosystems Limited. 'Annual Reports for the year 2007-08 and 2008-09', Available at corporation Website: http://www.hclinfosystems.in/.

[10] HCL Technologies Limited: 'Annual Reports for the year 2007-08 and 2008-09', Available at corporation Website: http://www.hcl.in/.

[11] Infosys Technologies Limited. 'Annual Reports for the year 2007-08 and 2008-09', Available at corporation Website: http://www.infosys.com/.

[12] I-Flex Solutions Limited. 'Annual Reports for the year 2007-08 and 2008-09', Available at corporation Website: http://www .I-FlexSolutions.com/.

[13] Joshi, M. and Ubha, D.S. (2009), 'Intellectual capital disclosures: The Search for a new paradigm in financial disclosure by the knowledge sector of Indian economy', Electronic Journal of KM, Vol.7, No. 5, pp. 575-582.

[14] Joshi, M., Ubha, D.S., and Sidhu, J. (2010), 'Reporting intellectual capital in annual reports from Australian S/W \& I/T corporations', Journal of Knowledge Management Practice, Vol. 11, No. 3, September, pp. 1-19. 
[15] Kamath, B. (2008), 'Intellectual capital reporting in India: content analysis of tech firms', Journal of Human Resource Costing and Accounting, Vol.12, No. 3, pp. 213-224.

[16] Larsen \& Toubro Infotech Limited. 'Annual Reports for the year 2007-08 and 2008-09', Available at corporation Website: http://www.lntinfotech.com/.

[17] MphasiS Limited. 'Annual Reports for the year 2007-08 and 2008-09', Available at corporation Website: http://www.mphasis.com/.

[18] Marr, B., Gray D., and Neely, A., (2003), 'Why do firms measure their intellectual capital?', Journal of Intellectual Capital, Vol. 4, No. 4, pp. 441-464.

[19] Moser Baer India Limited. 'Annual Reports for the year 2007-08 and 2008-09', Available at corporation Website: http://moserbaer.com/.

[20] Nielsen C., Bukh P.N., Mouritsen J., Johansen M.R., Gormsen P. (2006), 'Intellectual capital statements on their way to the stock exchange', Journal of Intellectual Capital, Vol. 7, No. 2, pp. 221-240.

[21] OECD Report (1999), 'Symposium on measuring and reporting IC: experience, issues, and prospects', Organization for Economic Cooperation and Development, pp. 1-196.

[22] Parker, L. D. (2007), 'Financial and external reporting research: the broadening corporate governance challenge', Accounting and Business Research, Vol. 37, No. 1, pp. 39-54.

[23] Patni Computer Systems Limited. 'Annual Reports for the year 2007-08 and 2008-09', Available at corporation Website: http://www.igatepatni.com/.

[24] Polaris Software Lab Limited. 'Annual Reports for the year 2007-08 and 2008-09', Available at corporation Website: http://www.polaris.co.in/.

[25] Reliance Industries Limited (1998). The Intellectual Capital Report 1997-98. Reliance Industries Limited, Mumbai (www.ril.com).

[26] Satyam Computer Services Limited. 'Annual Reports for the year 2007-08 and 2008-09', Available at corporation Website: http://www.mahindrasatyam.com/.

[27] Siemens Information System Limited. 'Annual Reports for the year 2007-08 and 2008-09', Available at corporation Website: http://www.siemens.co.in/.

[28] Stewart, Thomas A., (2002), 'The wealth of knowledge: intellectual capital and the twenty-first century organization', Currency Doubleday, 2002, pp. 1-32.

[29] Sveiby, K.E. (2004) 'Methods for measuring intangibles,' Available at www.sveiby.com.

[30] Tata Consultancy Services Limited. 'Annual Reports for the year 2007-08 and 2008-09', Available at the Corporation Website: http://www.tcs.com/.

[31] Tech Mahindra Limited. 'Annual Reports for the year 2007-08 and 2008-09', Available at the Corporation Website: www.techmahindra.com.

[32]Wipro Limited. 'Annual Reports for the year 2007-08 and 2008-09', Available at the Corporation Website: http://www.wipro.com/. 